component parts and determining their validity for selection purposes.

The programme covering engagement, placement and promotion of operatives at the Rowntree Cocoa Works in York makes use of : (1) biographical questionnaire; (2) psychological tests; (3) a personal interview by a psychologist. The biographical questionnaire is suitably designed to cover details of the candidate's education, occupation and recreation. It carries a blank margin down one side for interview notes, and overleaf it is suitably prepared for follow. up purposes. The psychological tests include tests of intelligence, attainment in English and arithmetic, and specially designed aptitude tests. The two paper-and-pencil type intelligence tests used in engagement and promotion procedures take ten minutes and twenty minutes respectively and have been standardized on the factory population at large - percentile scores being available for different industrial groups. Distribution diagrams of these results indicate clearly the group difference in test scores.

A battery of sixteen performance tests that had been in use in the Rowntree works for many years, and for which were available test and re/test scores of a large number of girls, was examined for reliability. As age, interval between first test and re/test, and job done between testings might all have had a disturbing effect on re/test scores, these had to be taken into account in determining the test reliabilities. It was found by analysis of covariance that department (but not job worked at) and interval (but not subject's age) affected re/test scores. So all statistics were calculated within the departments and the effect of interval ironed out by multiple correlation technique based on the assumption that the multiple correlation of the hypothetical true re/test score upon the true first test score and interval equalled unity. Following this examination, six tests were retained, having satisfactory reliabilities, and they have been in use as part of the engagement procedure. The opinion has been formed that performance tests lasting a very short time (less than one minute) are too unreliable to be of any use in selection work.

A factor analysis was carried out on the six tests, plus a verbal intelligence test. The intercorrelations could be explained by postulating two common factors running through the tests and factors specific to each test. Most of the non-error variance of four of the tests was accounted for by the two common factors, whereas most of the non-error variance of the other three was accounted for by their specific factors. Accordingly, it was decided to use the first four tests as a composite test and the others separately.

The composite test of 'practical ability' is now given to all factory entrants and consists of two exercises in 'posting' a set of fifty coloured cards; a test of three trials on the Seguin form board, and an attainment on a figure board of twelve inset coloured squares to be filled by geometrical shapes of appro. priate colour. The specific tests are: a ten-minute intelligence test, strength of grip on a dynamometer and a time reaction test. Three further tests of analogous type are also in use experimentally. They cover the factory job situations in which the operative is (1) being fed by a machine, (2) feeding a machine, (3) assembling small units to form larger units. Preliminary work has shown that these may give some help in placing operatives.

Besides biographical questionnaires, the selection programme includes a personal interview of candi- dates by a psychologist. The interview is regarded as having three aspects : in it the candidate enlarges on his application form ; the psychologist endeavours to check the stability of the candidate; and both endeavour to come to an agreement on the most appropriate placing of the candidate. Interviews (apparently confirming the finding of Russell Frazer's report on the incidence of neurosis among factory operatives) have indicated that about one-third of women factory applicants for work require special consideration for placing and follow-up on grounds of personal instability. Studies on the validity of the selection programme at present in use have not been easy from an administrative point of view. Two criteria (ratings of operatives by supervisors; and amount of work done in a three-month period) were defined for this purpose in a recent investigation. The correlation between workroom ratings and a combination of interview assessment, verbal intelligence test score and strength of grip was $0 \cdot 46$. The multiple correlation of the same three items plus 'practical ability' test with the criterion of work done was $0 \cdot 29$. Although not high, these figures, in view of the unstable nature of both criteria, were con. sidered satisfactory.

The general conclusion from the two papers and from the discussion that followed at Newcastle was that in a large industrial organisation of the kind described (one factory of several depart. ments, and a total number of about eight thousand employees), selection and placing of operatives with the aid of questionnaires, psychological tests and interviews have important contributions to make to both the production of the factory as a whole and to the well-being of the employees as individuals. It is, however, essential that whatever the procedures adopted they should be both technically sound and administratively convenient.

\section{FESTIVAL OF BRITAIN, 1951}

\section{SOUTH BANK EXHIBITION}

$T$ HE Festival of Britain, to be held during MaySeptember, 1951, will be a nation-wide demonstration of thp leading achievements of Great Britain in the arts, scences, technology and industrial design. The perfo piece of the Festival will be the Exhibition on As south bank of the River Thames between County Hall and Waterloo Bridge, and this will be mainly concerned with those contributions of science, technology and industrial design in which the prestige of Britain stands highest. Three other supplementary Exhibitions, two in London and one in Glasgow, will deal in more detail with architecture, science and heavy engineering respectively ; and the amusement section normally associated with any large exhibition will be in Battersea Park, London. In addition, two Travelling Exhibitions will visit provincial centres during the Festival summer and will tell, in different language, the same story as that in the South Bank Exhibition in London.

Plans for this last-named Exhibition have recently been announced. The south-bank site covers only twenty-seven acres, which is very small in comparison with recent national and international exhibitions. Thus the display will necessarily be highly selective. The Exhibition will not be a trade fair where industries or businesses can buy display space; but instead it 
will be organised into pavilions, each one of which will illustrate a particular theme; and only those subjects in which the British contribution is outstanding or unrivalled will be shown. The organisation of the Exhibition is in the hands of a team of experts representing science, architecture, exhibition technique and industrial design, which is known as the Presentation Panel, and which meets under the chairmanship of the director-general of the Festival. A Council of Science and Technology has been set up to represent the interests of the main branches of science, and the selection of currently manufactured exhibits is the responsibility of the Council of Industrial Design.

The site is divided by Hungerford Railway Bridge, and the Exhibition is based on this division by being laid out into two roughly semicircular sequences of buildings. The sequence lying upstream will illustrate the land and resources of Britain and what the people have derived from them, and that downstream will be concerned with the people themselves in their domestic surroundings. The main buildings of the Exhibition, some thirty in all, including restaurants and administrative buildings, but excluding the Concert Hall, are to be temporary structures. They will be constructed of a wide variety of materials and will contrast architecturally in colour and outline. The upstream area is to be the more formal in appearance, whereas the downstream area, in keeping with its theme, will wear a more domestic air.

The upstream sequence will be introduced by a section on the land of the British Isles, and following this will be sections designated and occupying areas (in square feet) as follows : country $(32,000)$, natural resources $(10,000)$, industry $(33,000)$, seas and ships $(24,000)$, transport $(48,000)$, and the Dome of Discovery $(99,767)$. The most striking building in this sequence (and, indeed, in the whole Exhibition) will be the Dome of Discovery. Designed to be the largest dome in the world, it will measure $365 \mathrm{ft}$. in diâmeter and $97 \mathrm{ft}$. in height. Its material, namely aluminium, will represent for this generation what sheet glass and cast iron did for the 1851 Exhibition, and the Dome will be as arresting in 1951 as was the Crystal Palace a hundred years ago. In it the story to be told is British pre-eminence in discovery and exploration, not only by land and sea, but also into the very nature of the living world and the universe. One section will display the latest knowledge of the structure and nature of matter, culminating in a display of nuclear energy, and others will be concerned with land, sea and polar exploration, inner space, outer space and the living world; all the sections will show appropriate industrial exhibits.

In the downstream sequence the sections and their corresponding areas (in square feet) are planned to be : character and tradition $(10,715)$, homes and gardens $(24,000)$, new schools $(11,300)$, health $(7,000)$, sport $(5,300)$, seaside (approximately 10,000 ), the Shot Tower, the Telecinema and the Concert Hall. The last three are particularly interesting, especially the Shot Tower. This is a London landmark which survived the 'blitz' that razed this part of Thamesside during the War. Built like a lighthouse and designed originally for the manufacture of lead shot, it will be used to carry at its summit a 30 -ft. diameter aerial of umbrella shape, which will be rotated by remote control from the 'outer space' section of the Dome of Discovery. With this radio telescope visitors in the Dome will be able to observe radio waves from the sun, stars and even meteors, and will be able to transmit radio signals to the moon and note their reflexion back to the earth a few seconds later. The Telecinema will be a small pavilion dealing with both cinematography and television; it will seat four hundred people for the showing of programmes, and is being built on very modern principles incorporating the most recent techniques in projection and acoustics.

The only permanent building on the whole site will be the new Concert Hall, which has been commissioned by, and will be the property of, the London County Council ; this Hall will fulfil a long-felt want for a centre of culture on the south side of London. In fact, the development of the south-bank site for this Exhibition is being carried out in the closest collaboration with the London County Council, and the planning of roads, gas, water and electricity services, landscape, terracing, etc., is being made with a future long-term value definitely in mind. Such a point of view is very much in keeping with the spirit of the Exhibition.

\section{AN ESTER WAX FOR USE IN THE TROPICS}

\author{
By DR. H. F. STEEDMAN
}

Zoology Department, University of Glasgow

IN cutting histological sections in the tropies, the 1 room temperatures during the day are in many cases so high that microtome work has to be done during the evening or at night. With paraffin wax the solution of this difficulty is usually sought in the employment of a wax of a higher melting point than that commonly used in temperate regions, because a higher melting point is usually correlated with a harder wax. Unfortunately, this means that material during infiltration is subjected to a much higher temperature than is desirable, waxes of $60-70^{\circ} \mathrm{C}$. $\left(140-158^{\circ} \mathrm{F}\right.$.) melting point being necessary.

The advantage of low-temperature infiltration yet with an exceedingly hard product as the final block is provided by using the following variation of the standard ester wax formula.

$\begin{array}{lr}\text { Diethylene glycol distearate } & 80 \mathrm{gm} . \\ \text { Ethyl cellulose, low viscosity } & 4 \mathrm{gm} . \\ \text { Stearic acid } & 5 \mathrm{gm} . \\ \text { Castor oil } & 4 \mathrm{gm} . \mathrm{g} . \\ \text { Diethylene glycol monostearate } & 5 \mathrm{gm} .\end{array}$

This wax is designed for use at room temperatures of $75-90^{\circ} \mathrm{F}$. (c. $24-32^{\circ} \mathrm{C}$.). Its performance at room temperatures of $75^{\circ}, 85^{\circ}$ and $90^{\circ} \mathrm{F}$. is given below.

$$
\begin{aligned}
& \text { Room temperature } \\
& 75^{\circ} \mathrm{F} \text {. } \\
& \text { Room temperature } \\
& 85^{\circ} \mathrm{F} \text {. } \\
& \text { Room temperature } \\
& 90^{\circ} \mathrm{F} \text {. }
\end{aligned}
$$$$
\begin{aligned}
& \text { Section range } 4-25 \mu \\
& \text { Ribbon range } 4-18 \mu \\
& \text { Compression at } 8 \mu \text { is } 12 \text { per cent } \\
& \text { Section range } 4-25 \mu \\
& \text { Ribbon range } 4-25 \mu \\
& \text { Compression at } 8 \mu \text { is } 12 \text { per cent } \\
& \text { Section range } 5-25 \mu \\
& \text { Ribbon range } 5-25 \mu \\
& \text { Compression at } 8 \mu \text { is } 14 \text { per cent }
\end{aligned}
$$

The range of thickness of single sections and also of section ribbons at the three room temperatures cited should be sufficient for most purposes. It will be found that a microtome knife of first-class sharpness will give an improvement on these figures as well as reducing the compression percentage. The compression figures quoted are those derived from measurement of ribbons after flattening.

The performance of tropical ester wax at room temperatures lower than $70^{\circ} \mathrm{F}$. is poor. It is not 